\title{
An Ergonomic Study of The Effect of Scaling Procedure on The Musculoskeletals Problems, Workloads, and Eye Strain Among Dental Students
}

\author{
Putu Lestari Sudirman ${ }^{1}$, I P. G. Adiatmika ${ }^{2}$, I Nyoman Adiputra ${ }^{3}$, I Ketut Tirtayasa ${ }^{4}$ \\ Faculty of Medicine Udayana University \\ Denpasar, Bali \\ lestarisudirman@gmail.com \\ Faculty of Medicine Udayana University \\ Denpasar, Bali \\ Faculty of Medicine Udayana University \\ Denpasar, Bali \\ Faculty of Medicine Udayana University \\ Denpasar, Bali
}

\begin{abstract}
Dental treatments generally need length of time period. The dental care consist of several steps and these steps should be performed in the cramped space which is patient's mouth (oral cavity). Thus, dentists have potential on suffering for musculoskeletal injuries which may affect their quality of work. This is a descriptive study (observation and interviews) with cross-sectional approach. This study conducted observation on several ergonomic aspects include task, organizational, and environment; following with interviews on how were dental students performing scaling procedures The mean time of dental students in performing scaling was 28,38 $\pm 1,03$ minutes, this period of time also cover all the time needed for several adjusting working positions taken by dental students on purpose to cover scaling on all of the teeth surfaces and regions. Dentists have risk for potential injuries resulted from non-ergonomic working attitude and static position. This indicated from increasing of Nordic Body Map scores after performing scaling with mean scores 13,87 $\pm 1,56$, increasing eyes train scores up to $2,2 \pm 0,27$, and increasing work load which was calculated from hearth rate 23,45 $\pm 2,70$ beats/menit. This study also assesses organizational and working environment which may affect dental students on performing scaling. The total ergonomic approach may be employed to solve the identified problems from ergonomic assessment on the scaling procedures performed by dental students at Dentistry Udayana University. Thus, it is expected that the approach can be solve the problems complained by dental students while performing scaling procedure, as well as assistant operators, patients, and others related parties without creating unnecessary side effects causing by the purposed adjustment.
\end{abstract}

\section{Index Terms - scaling, ergonomic study, dentist}

\section{INTRODUCTION}

People awareness of dental care has been increasing, this can be seen by increasing number of dental visits. Dental visits do not only aim to check for the dental problems such as toothache; people visit dentists for dental checkups, scaling, and aesthetical dental care. These trends demand dentists in maintaining their health and work productivity [1].

The patient complaints related scaling at Dental Clinic Udayana University Hospital 2017 to 2018 include: 43\% time consuming and boring, 37\% uncomfortable (toothache), $20 \%$ pricey. A scaling technology, ultrasonic scaler, can help to reduce scaling time and it can minimize uncomfortable feeling during scaling [2]. Considering of the importance of dental checkups including scaling in every six months, it is needed to explore several aggressive solutions for identified scaling complaints. The first step is to identify the problems and hazard in dental clinic specially in which related to scaling procedure.

Potential hazard in dental clinic mostly resulted from working position [3]. It is recommended for dentists to 
maintain their neutral position, sit with straight back and thighs parallel to the floor, or keep hip and knees at 90 degrees, and sit behind the patient's head. Optimal head posture is ears are parallel to shoulders from side views, and head inclination is not more than $20 \mathrm{o}$, decline less than 25o, and patients are lying with their head in front of dentists [4]. However, it is challenging for dentists to maintain ideal working posture. The potential difficulties include patients may feel uncomfortable on holding the needed position and they keep on choking, dentists encounter visual hurdles because of foggy dental mirror or dirty mirror caused by splotch water from dental bor. Moreover, performing scaling means dentists need to do comprehensive cleaning for all teeth surface, scaling reaches below the gumline to remove plaque and stain in subgingival and supragingival [5].

The considered obstacles during scaling tend to make dentists to neglect ergonomic working position, and to keep their working habit based on personal comfort. In addition, there are several dental tools that considered as nonergonomic tools, non-ergonomic working station, which this may interfere dentist working movements [6]. Most of dental tools are product of Europe and America, as the tools mostly created based on Europeans and Americans body proportion; thus, the tools may be less adjustable for Indonesian dentists as the Indonesians body proportion differ from European and American in genereal. Moreover, several dental clinics do not involve their dentists on the process of constructing and building working station for dental procedures, this may become the reason why the dentist cubicle or working station has disproportion on positioning and size of room and dental tools.

Non-ergonomic working station and working attitude which neglect the ergonomic principles will potentially harm dentists and it may cause them several problems such as musculoskeletal problems, eye strain, increasing work load. Doing scaling without ergonomic principles will also potential on risking dentists having musculoskeletal problems. World Health Organization (WHO) define musculoskeletal disorders (MSDs) as disorders that occur in the neck, nape, right and left shoulders, back, arms, waist, hips, elbows, thighs, knees, calves and legs from muscles and blood vessels which can develop become chronic over time [4].

Dentists or operators need to work in long period of time with narrow view and small objects which may cause eye strain. The dentists' eyes need to focus on small objects in long time period during scaling, their eyes will continuously adjust their eyes' accommodation which can risk eye strain. Individuals who are working with small objects in long period of time, need resting their eyes by watching objects from distance to prevent eye strain [6].

Excessive workload experienced by dental students is resulted from the amount of physical and psychological burdens during their time on clinical practice study [7], by measuring and evaluating workload could define the work productivity

\section{METHOD}

This is a descriptive study (observation and interviews) with cross-sectional approach. study observation conducted on dental students of Udayana University while performing scaling related to three ergonomic aspects (tasks, organizational, and environment). Furthermore, respondents, 20 dental students, were interviewed and asked to fill up Nordic Body Maps questionnaire and eye strain questionnaire. The respondents' workload was also measured by calculating their heart rate. The data were gathered before and after respondents performing scaling using ultrasonic scaler.

\section{III. RESULT AND DISCUSSION}

This study calculated of the resting heart rates (RHR) and working heart rates (WHR) of dental students on performing scaling to measure workload level. The respondents were also asked to fill up Nordic Body Maps questionnaire and eye strain questionnaire before and after scaling procedures. The data shows on Table 1.

TABLE I

ASSESSMENT RESULT OF DENTAL STUDENTS IN PERFORMING SCALING

\begin{tabular}{ll}
\hline \multicolumn{1}{c}{ Measuring Aspects } & \multicolumn{1}{c}{ Mean \pm SD } \\
\hline Musculoskeletal problems (score) & $13,87 \pm 1,56$ \\
Eye strain (score) & $2,2 \pm 0,27$ \\
workload (x/minutes) & $23,45 \pm 2,70$ \\
Working time (minutes) & $28,38 \pm 1,03$ \\
Resting Heart Rate (RHR) (x/minutes) & $69,47 \pm 3,35$ \\
Working Heart Rate (WHR) (x/minutes) & $92,92 \pm 2,49$ \\
Maximum Heart Rate (MHR) (x/minutes) & $184,35 \pm 9,98$ \\
CVL (\%) & $20,55 \pm 2,81$ \\
\hline
\end{tabular}

Scaling and root planing are the substantial procedures for successfulness of periodontal therapy. Scaling and root planing procedures involve removing plaque, calculus, endotoxin and necrotic cementum from root surface [8]. The average time for dentists to perform extensive scaling and root planning was $28,38 \pm 1,03$ minutes. Table 1 shows the mean musculoskeletal problems score was $13,87 \pm 1,56$, which was calculated from the range of NBM score before and after scaling. This study indicates that scaling may affect musculoskeletal problems among dental students; and the highest mean musculoskeletal score specify wrist complaint which was $2,85 \pm 0,37$. This study shows that the dental students were having wrist problems resulted from scaling procedures, the problems vary from slightly uncomfortable to very painful wrist but these problems seemed not prevent them on performing scaling. However, it is important to discover the solutions to prevent these problems that can potentially of getting worst over time.

Eye strain score measurement on this study showed the increasing score from before to after scaling procedure with total escalating score about $2,2 \pm 0,27$. This study indicates that the scaling procedures may affect eye strain among dental students. The workload level evaluation resulted $23,45 \pm 2,70$ beats/minutes, this result indicates minimum 
workload. Percent cardiovascular load (CVL) was 20,55 \pm $2,81 \%$, which was below $30 \%$, this indicates that dental students did not fatigue, it is probably because they are relatively still young, mostly have good physical fitness and have worked in less than a year.

The dental students performance while operating scaling were observed in several steps including the plaque removal step, root planing step, and polishing. Dental students need to do several steps on performing scaling. Those steps include report to their dentist supervisors and ask for their approval for initiate scaling, prepare dental scaling tools, and performing extensive scaling (region 1,2,3 and 4). Before begin the next steps, dental students have to report their first scaling works to their dentist supervisors, the supervisors need to evaluate the students scaling result for those four regions and make sure that all the plaque have been removed successfully before recommending the students to the polishing steps. Following that, dental students will perform polishing steps by using brush, rubber polishing and paste, it is applied to all needed teeth surface to prevent deaccumulation of debris and calculus [1].

The observation study of task aspect shows that dental students demonstrated non-ergonomic working posture especially while they performed deep cleaning and had to assess oral cavity; moreover, they showed non-ergonomic posture as they needed to keep control of handpiece tip and ultrasonic scaler to avoid mechanical injury on patient's gingiva (figure 1).
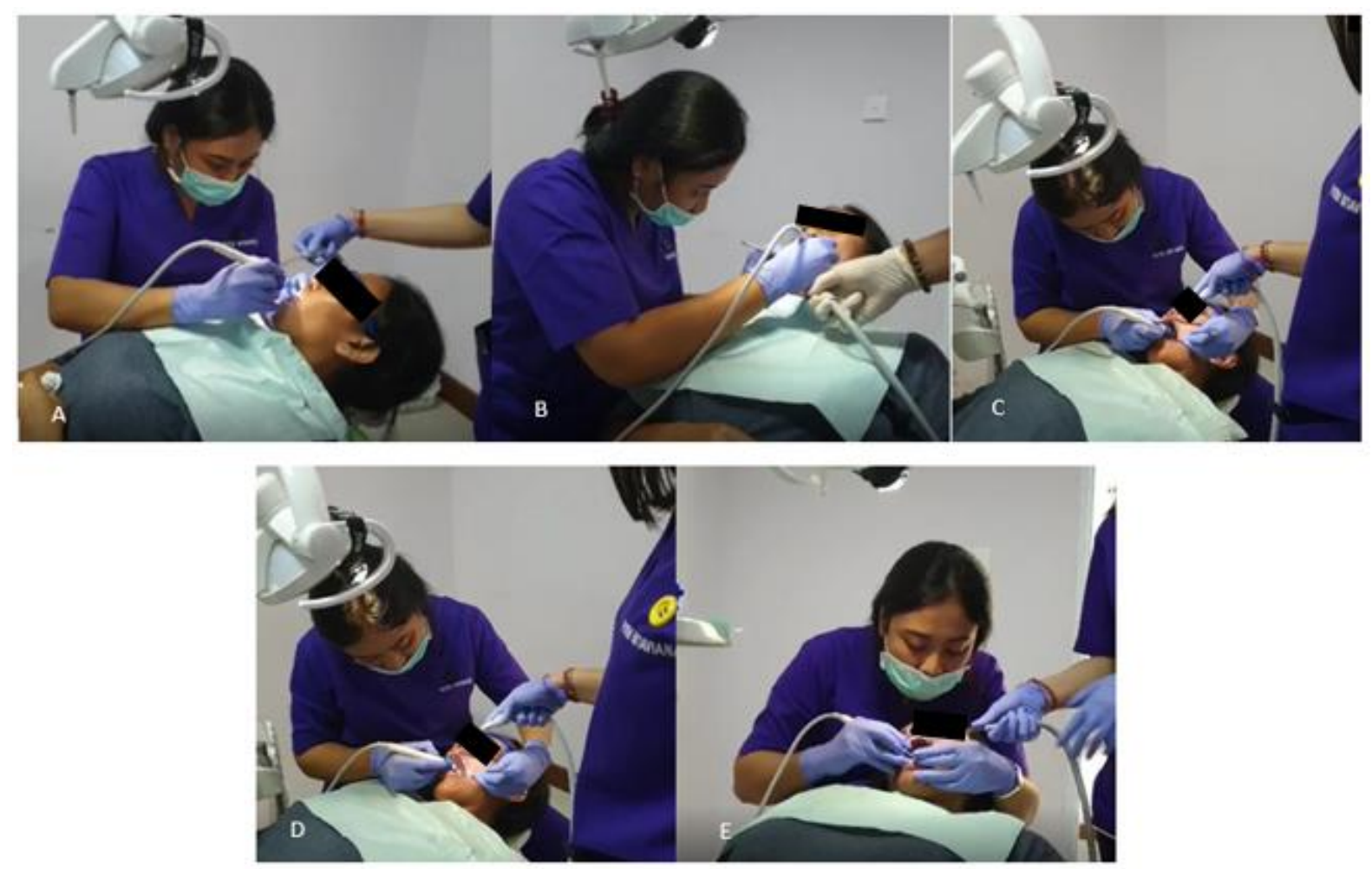

Figure 1. Dental students work posture in scaling process (A). Regio 1, (B). Regio 2, (C). Regio 3, (D). Regio 4, (E). Regio 3 and 4 anterior (personal document)

Data gathered from interviews show that dental students tended to find the steps of plaque removal and root planing as the most challenging steps as it needed around 28 minutes and needed several adjusting positions as they were struggling to assess all of the patient's mouth regions. This can potentially affect musculoskeletal problems as dentists need to maintain static position and bent down in long time period [9]. Another dental student complaint was they found the dental cubicle did not have enough space to allow them to move freely. The crumped room gave them limited space to maintain ergonomic adjustment working postures (figure2). The study shows the significant increase in the Nordic Body Map score of dental students after performing scaling, especially in the upper neck, lower neck, right shoulder, left upper arm, back, right upper arm and right wrist. Causes of musculoskeletal complaints.

Figure. 2, shows space of the dental cubicle do not support dentists in performing maximum dental maneuver, this makes dental students and operators could not maintain ergonomic working postures. The picture shows that the operator's right shoulder is raised, because the patient's position is not low enough or the dental unit's back cannot be reclined and adjusted to the height of the dental stool. The operator can not sit behind patient or from 10-12 clockwise of patient's head (figure 3). Dental unit is too near with the sink those it makes operators to work from 9 clockwise position, they need to work from patient' right hand position to work on region 3 and 4 anterior. This 
condition can potentially harmful for dental students, as they have to work with non-ergonomic postures long time period [10]. Working with non-ergonomic posture tend to consume more energy than working with ergonomic posture [11]. Recommended ergonomic work postures on performing scaling for region 1 to 4 anterior are depicted on figure 3 and 4.

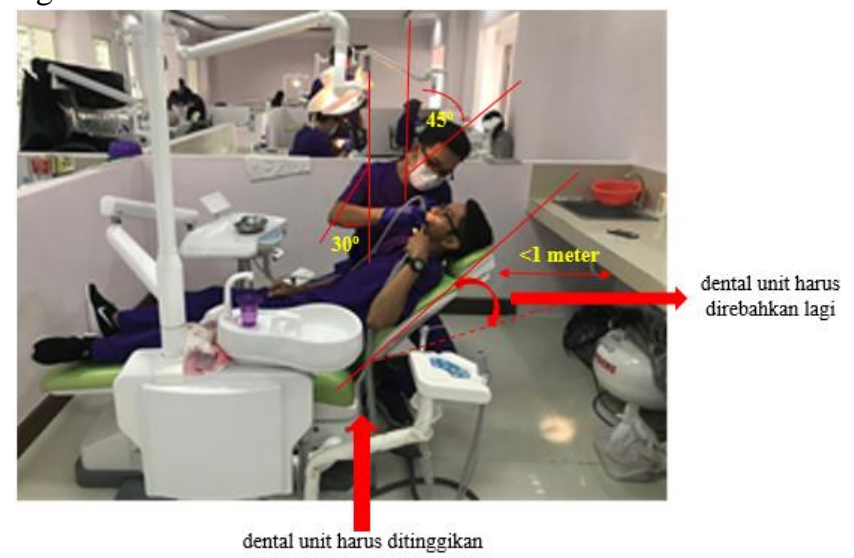

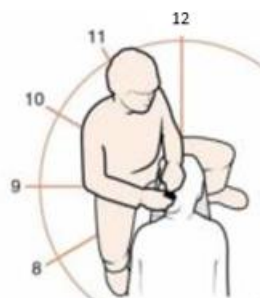

A
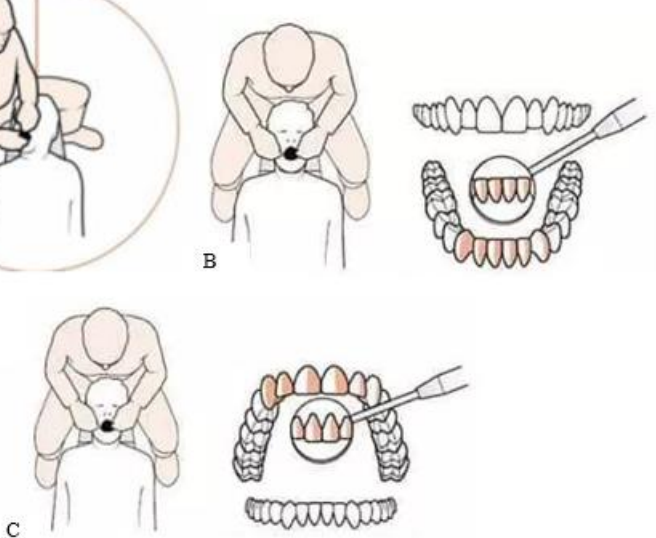

Figure 3. A. Dentist and patient work position, B. Dentist work position in regio 3 and 4 anterior, C. Dentist work position in regio 1 and 2 anterior [12].

Figure 2. Narrow cubicle, in the right posture
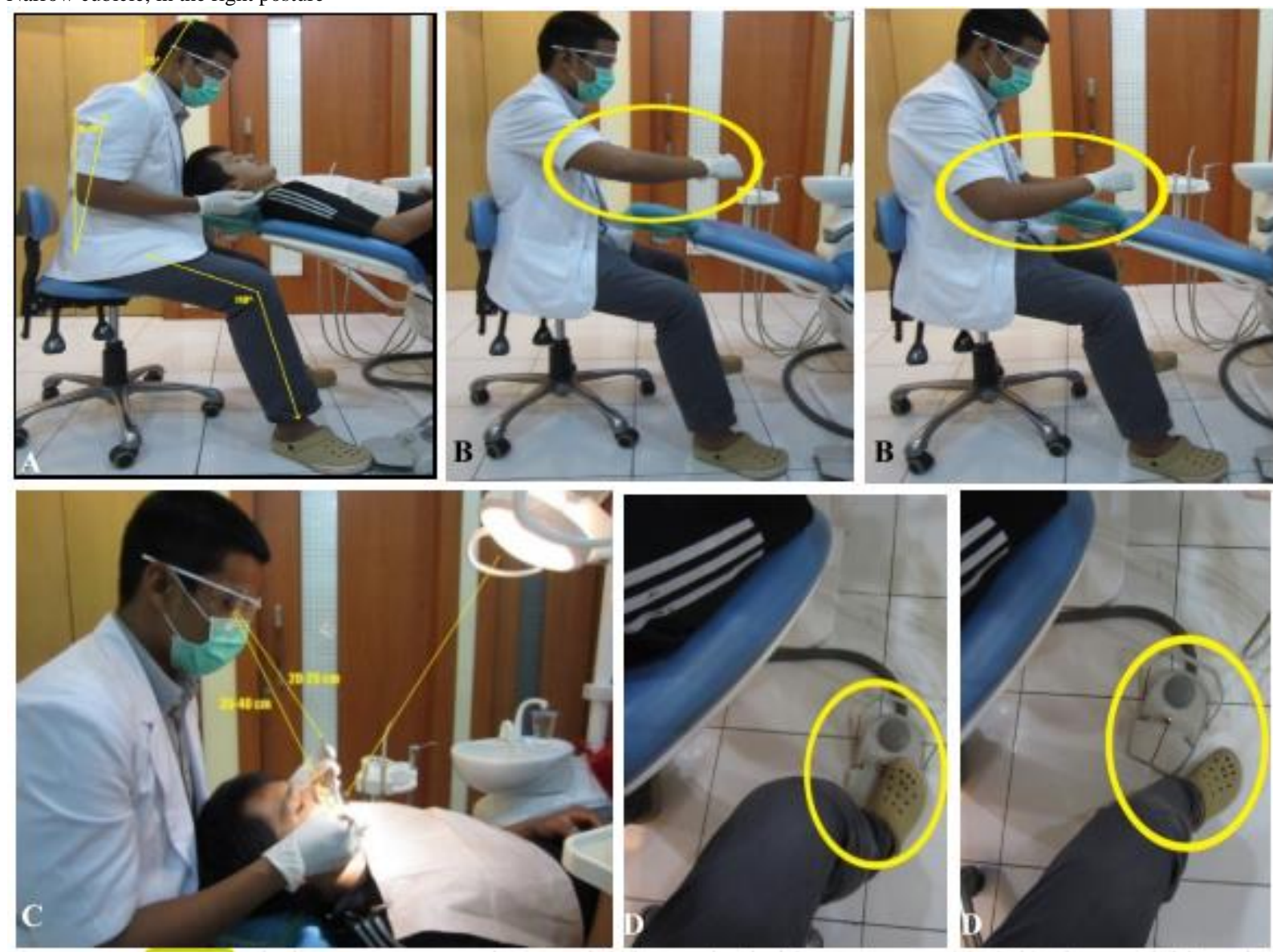

Figure 4. Ergonomic work position; A. Feet angle, back (sitting), and head position; B arm angle, in 10-25 from horizontal;C work station space (mouth) 35 $40 \mathrm{~cm}$ and instrument $20-25 \mathrm{~cm}$ to safety glassess, dental chair lamp position to work station; D pedal drive position, near feet [13]

The study for organizational aspect shows that dental students can not regulate for a scheduled break time as they have lack control of their patients and their clinical supervisors. Mostly their patients came to dental clinic not precisely on their scheduled times as well as their clinical supervisors. Thus, the dental students still needed to work during the scheduled break time. This condition may drive them for taking break not during the scheduled break time. Another finding of this study shows that the dental students had limited access for standard personal protective 
equipment (PPE). They were performing scaling without goggles and they also did not wear face mask properly (as seen on figure 1), these could risk them for potential occupational injuries. Scaling using ultrasonic scaler produce cooling water and aerosol with vibration power from the tip of ultrasonic scale to comfort patients. Thus, the scaling process with ultrasonic scaler may produce dental aerosol and airborne particles which may risk for diseases transmission on dental clinics.

\section{CONCLUSION}

This study concludes that dental students are facing ergonomic problems while performing scaling during their clinical practice in dental clinic of Udayana University Hospital. The study of task (ergonomic) aspect indicates dental students were supported with scaling tools and working station which were not anthropometrical appropriate for them, thus it can influence their work productivity. It has been observed that dental students demonstrated scaling with non-ergonomic work postures and positions which did not meet theory and recommended work direction to cover all of patients' oral regions. Furthermore, the dental students mostly demonstrated nonergonomic work attitude while scaling for posterior teeth plaques. Dental students tended to bending over to reach better views of scaling regions and tilting their neck especially if they had to cover teeth posterior, they had the tendency to do those non-ergonomic posture rather than adjusting the dental units or asking patients for adjusting their head positions. Dental students did not have a scheduled break time as they had lack control on patients' and clinical supervisor schedule. In addition, dental students did not demonstrate proper use of PPE, they tended to have lack personal awareness of the importance of goggles for performing scaling and this may be because that it was not clearly written on their clinical practice study guideline about the mandatory of wearing goggles. Lighting and audio problems resulted from continuous dental compressor usage need to be fixed. Total ergonomic approach can become problem solving method to fix several problems arising from scaling procedure performing by dental students at dental clinic in Udayana University Hospital. This total ergonomic approach is expected to solve identified problems and to prevent the potential problems.

\section{REFERENCES}

[1] Octavia, M., Soeroso, Y., Kemal, Y., \& Airina, A. "Adjunctive Intracoronal Splint in Periodontal Treatment: Report of Two Cases". Journal of Dentistry Indonesia, 21(3), 94-99. https://doi.org/10.14693/jdi.v21i3.193. 2016.

[2] Laksmana, T. "Fakultas kedokteran gigi universitas hasanuddin makassar" 0, 0-43. 2016.

[3] Roshene, R., \& Loganathan, S. "Ergonomics and musculoskeletal disorder as an occupational hazard in dentistry- a pilot study". Journal of Pharmaceutical Sciences and Research, 9(5), 712-715. https://doi.org/10.5005/jp-journals-10024-1317. 2017.

[4] Valachy, B. "Practice Dentistry Pain-Free". Portland: Posturedontics Press. 2008.
[5] Ikhsan, I. N. H. B. "Gambaran Status Periodontal Penderita Gingivitis yang Merokok yang Dirawat DiInstalasi Periodonsia" RSGM Universitas Sumatera Utara, 42. 2017.

[6] Iridiastadi, H., Yassierli. "Ergonomi Suatu Pengantar". Bandung: PT. Remaja Rosdakarya. 2014.

[7] Sawitri, M. R., \& Mulyono, M. "Analisis Risiko Pada Pekerjaan Dokter Gigi Di Kabupaten Dan Kota Probolinggo". The Indonesian Journal of Occupational Safety and Health, 8(1), 29. https://doi.org/10.20473/ijosh.v8i1.2019.29-37. 2019.

[8] Aristóteles. "Efektifitas Gel Daun Sirih Merah (piper crocatum) pada Perawatan Priodontitis Kronis". Kartika-Jurnal Ilmiah Farmasi, 52(1), 1-5. 2017.

[9] Sumarna. U., sumarni.N., Rosidin. U., "Bahaya Kerja Serta Faktor Faktor Yang Mempengaruhinya”. Yogyakarta, P (89-97). 2018.

[10] Manuaba, A. "A Total Approach In Ergonomics is A Must To Attain Human, Competitive, and Sustainable Work System and Products". Dipresentasikan pada: Ergo Future 2006: International Symposium On Past, Present and Future Ergonomics, Occupational Safety and Health. Denpasar 28-30thAugust . 2006.

[11] Takahashi, S. "Physical Activity, Energy Expenditure and Work Intensity of Care -Works on Shift Work in a Special Nursing Home for the Elderly". Japan. Journal of Occupational Health. 2002.

[12] Antonim. artikel. Diambil 11 April 2019, dari https://dental.id/yukcek-lagi-posisi-operator-terhadap-pasien/.2018.

[13] Windi, Samad, R. "Penerapan postur tubuh yang ergonomis oleh mahasiswa tahap profesi Fakultas Kedokteran Gigi Universitas Hasanuddin selama prosedur perawatan" (Application of ergonomic posture by clinical dental students of Faculty of Dentistry Hasanuddin University durin, 14(1), 32-37. 2015. 